\title{
The effect of parenting experience during childhood on the later awareness of children's rights: The mediating effects of self-esteem and emotional intelligence
}

SEOYEON LEE ( $\square$ sci3on@hanmail.net )

Delaware State University

\section{Research Article}

Keywords: Parenting attitudes, Parenting experiences, Children's rights, Emotional intelligence, Selfesteem

Posted Date: April 20th, 2021

DOI: https://doi.org/10.21203/rs.3.rs-429650/v1

License: (c) (1) This work is licensed under a Creative Commons Attribution 4.0 International License. Read Full License 


\section{Abstract}

A large body of literature has shown the close relationship between parents' parenting attitudes and their parenting experiences during their own childhood. However, it is hard to find either theoretical or empirical studies explaining why and how such close relationships develop. This study fills this gap. To do so, we extensively review the related theories and hypothesize that mothers' parenting experiences during their own childhood affect their later level of awareness of children's rights through the mediation effects of two psychological factors: self-esteem and emotional intelligence. Applying structural equation modeling to a vast dataset acquired by surveying 1,011 Korean mothers we provide evidence that strongly supports the main hypothesis. We also find that this relationship holds in a roundabout way: while there is no direct relationship between mothers' parenting experiences during childhood and their current level of awareness of children's rights, the effects of the former on the latter are indirectly mediated by selfesteem and emotional intelligence. These findings may imply that psychological programs for parents can improve their emotional intelligence and self-esteem and thus improve their practices regarding children's rights since psychological factors can change over one's lifetime.

\section{Introduction}

Today, many forms of abuse and crimes against children exist, so it is imperative to take measures to prevent such crime. Additional punishments for child abuse or crimes against children are not ideal solution. The most desirable countermeasure is the prevention of such crime. The most effective precautionary measure would be to raise the public's awareness of children's rights. The purpose of this study is to provide fundamental research results that are critical for preventing child abuse and developing policies to promote children's rights. This is done by investigating psychological factors that are affected by people's parenting experiences in early childhood that, in turn, affect their awareness of children's rights and consequently, their own parental attitudes.

It is well documented that people's parenting experiences in childhood serve as an important factor in determining their attitude toward their family and their own children when they become parents (e.g., Crowell and Feldman 1989; Fincham 1994). Parents with positive parenting experiences in childhood tend to have a positive attitude toward their own children and family. These previous studies suggest that the attitudes and values regarding family and children are inherited over generations. Unfortunately, however, the logic behind this suggestion remains unclear: studies explain why and how such a relationship works have been extremely limited. This lack of explanation limits the application of the valuable research findings in practice. Thus, this study aims to fill this gap.

Most psychological studies find that the most of an adult's (1) self-esteem (for comprehensive surveys for this subject see Orth 2017; Orth and Robins 2014; Robins and Trzesniewski 2005; Trzesniewski et al. 2013) and (2) emotional intelligence (Allemand et al. 2015; Grühn et al. 2008; Helson et al. 2002) is formed in childhood and has a strong tendency to remain consistent throughout adulthood. Extensive psychological studies have also shown that self-esteem and emotional intelligence may be the most 
important factors affecting social attitudes and behaviors (Chakraborty and Chlup 2016; Craig 2006; Orth 2017, 2018; Pizarro 2000; Pizarro and Salovey 2012). Given that one's social attitude includes one's awareness of children's rights, it is plausible to suggest that parenting experiences affect the development of the awareness of children's rights through the two psychological factors of self-esteem and emotional intelligence. Unfortunately, however, research on the influence of such psychological development on the attitude toward children's rights has not yet been actively conducted. This study suggests that childhood parenting experience affects psychological development, which in turn affects the construction of social attitudes, including the awareness of children's rights.

To empirically verify the theoretical hypotheses suggested here, this study surveyed and analyzed a wide range of data from more than 1,000 Korean mothers with 5-7-year-old children. By examining the link between their perceived childhood parenting experience and their current self-esteem and emotional intelligence, this study empirically verifies whether childhood parenting experience affects mothers' selfesteem and emotional intelligence. It also analyses whether such self-esteem and emotional intelligence influence the level of awareness of children's rights.

Currently, many children are being exposed to child abuse worldwide. Given that $70 \%$ of child abusers are parents, it is no exaggeration to say that child abuse substantially occurs at home. It is a situation where the types of child maltreatment expand to physical abuse, sexual abuse, neglect, and abandonment, and even psychological abuse. It is also noticeable that the seriousness of physical and psychological child abuse in 'Jung-In's fatal child abuse case (Segye Ilbo, January 8, 2020)' and 'Foster parents child abuse in South Carolina (Seoul Shinmun, February 8, 2021).' Psychological maltreatment (PM), despite its clear definition and evidence showing that it actually does harm to children, is far less reported to Child protective services than physical or sexual abuse in the United States (Baker, Brassard \& Rosenzweig, 2021). Childhood maltreatment (CM) may have negative impacts on the lifespan of those who have been abused. Moreover, the experience of being abused may affect one's parenting attitude. Theoretically, the parents who have experienced childhood maltreatment are less capable of coping with the difficulties in child-rearing, which leads to having issues with their parental attitude. Therefore, parenting attitudes may affect one's attitude towards respecting and perceiving children's rights (Savage, Tarabulsy, Pearson, Collin-Vézina and Gagné, 2019). - add Reviewers

This study is organized as follows. Section II describes the solid theoretical foundation from which our hypotheses are developed. Here, we examine how individuals' childhood parenting experiences affect the development of their self-esteem and emotional intelligence. In addition, we can infer from a review of relevant theoretical studies that these two psychological factors may affect the awareness of children's rights in adulthood. Section III describes the research methods and measurement variables used in the study. Section IV presents the estimation results of the structural equation model for the dataset surveyed for this study. Finally, section $V$ summarizes the findings of this study and provides suggestions based on the results.

\section{li. Theoretical Background}




\section{Parenting Experience, Self-esteem, and Awareness of Children's Rights}

Since James's pioneering work (1890), self-esteem has been studied from various perspectives. Despite the diversity definitions of self-esteem, recent research trends are converging on the following definition: 'self-evaluation of their own values and abilities' (Cooley 1902; Coopersmith 1967; Rogenberg 1979; Holland and Andre 1994; Brranden 1995).

For this study, two issues are particularly pertinent (for comprehensive reviews, see Orth (2017), Orth and Robins (2014), Robins and Trzesniewski (2005), Trzesniewski et al. (2013)). The first is concerned with the determinant factors and development of self-esteem. According to the latest findings of behavioral genetic studies, self-esteem is influenced by both genetic and environmental factors, but the latter are reported to have a significantly greater effect (McGuire et al. 1994; Neiss, Sedikides and Stevenson 2002; Neiss, Sedikides, Stevenson and Kumashiro et al. 2005). Among the environmental factors, parents' parenting attitude has been particularly highlighted as a crucial factor for the formation of childhood selfesteem. In other words, a child's self-esteem can vary greatly depending on the attitude of his or her parents toward the child. It has also been proposed that the psychological state of one's self-esteem is clearly formed in childhood, and a large portion of this is transferred to one's later life. For example, recent studies using large-scale longitudinal datasets show that the level of one's self-esteem varies throughout one's entire lifespan, plotting an inverted U-shape trajectory (Orth 2018; Orth, Robins and Trzesniewski 2010; Orth, Robins and Widaman 2012; Orth, Maes and Schmitt 2015, and references therein). For this study, it is particularly important to note that self-esteem is already established in childhood as a factor that constitutes individual's personalities, and individual differences are then fixed (Cole et al. 2001; Donnellan et al. 2012; Wagner et al. 2016). This could imply that a large part of the research participants' (mothers with children) self-esteem was formed in their childhood.

Second, the present study also carefully takes into account the effects of self-esteem on social behaviors and attitudes. The traditional view has been that self-esteem cannot accommodate antisocial behaviors such as violence, crime, drugs and smoking (Craig 2006; Orth 2017, 2018). If the awareness of children's rights is considered to be a 'social attitude', it is expected that the higher one's self-esteem is, the higher one's awareness of children's rights will be. However, a skeptical view of the role of self-esteem has also emerged (Baumeister and Vohs 2018; Baumeister and Campbell et al. 2003; Baumeister \& Smart et al. 1996; Crocker and Park 2004; Emler 2001). Researchers have argued that high self-esteem does not necessarily constrain antisocial behavior or delinquency. For example, within the vast literature, Baumeister and Vohs (2018) demonstrate that there has been no evidence to support the positive effects of social behavior and attitudes on self-esteem, implying that the two have little to do with each other. Similarly, Emler (2001) argues that there is no empirical evidence for the common belief that child abuse is committed by parents with low self-esteem, although it is widespread among clinical professionals (also see Baumeister et al. 1996). All of these discussions and debates imply that the relationship between self-esteem and the level of awareness of children's rights is at least open to debate and can be an interesting research subject. 
Thus, the present study contributes to the field in two ways. First, it empirically examines the effects of parenting experiences on the level of self-esteem of adults with children. Second, it also empirically investigates the alleged positive association between self-esteem and the level of awareness of children's rights.

\section{Parenting Experience in Childhood, Emotional Intelligence and Awareness of Children's Rights}

The psychological theory that human intelligence has various domains and that each intelligence domain should be defined accordingly has been present since the early 20th century (Thorndike 1920; Wechshler 1958; Gardner 1983). Emotional intelligence has taken center stage in research and is a popular subject among the public (Salovey and Mayer 1990; Goleman 1995, 1998, 2006); a wide range of formal models to measure emotional intelligence have been proposed and applied to practice. However, the diversity of the models has also caused theoretical controversies regarding the definition and substance of emotional intelligence (Cherniss 2010; Daus and Ashkanasy, 2003; Locke 2005; Mathews et al. 2006; Murphy 2006). Despite this theoretical diversity and controversy, it is possible to extract common factors from various emotional intelligence models and establish a practical concept relevant to this study. We define emotional intelligence as the type of intelligence that is responsible for the 'social function' à la Salovey and Mayer (1990).

Viewing the subject from this angle, we suggest that the higher an individual's emotional intelligence is, the more awareness of and empathy towards others' feelings he or she will have and the more effective his or her social activities, such as the formation of desirable interpersonal relations, will be (Lopes et al. 2004; Salovey and Mayer 1990). Emotional intelligence is the ability to better understand one's own mind and that of others and at the same time to control one's attitudes and behaviors appropriately. If one can make good use of one's emotion intelligence, one is likely to have prosocial attitudes and behaviors (for case studies see Davis et al. 1999; Eisenberg et al. 2009; McDonald and Messinger 2011; Wilhelm and Bekkers 2010).

In a similar vein, it can be argued that emotional intelligence is closely related to social justice and moral judgment (Chakraborty and Chlup 2016; Pizarro 2000; Pizarro and Salovey 2012). Pizarro (2000) and Pizarro and Salovey (2012) convincingly demonstrate that emotion plays a critical role in moral development, judgment, and behavior. The ability to deal with emotion can be regarded as the ability to be a morally 'good person' (Allemand et al. 2015; Gerdes et al. 2011; Pizarro and Salovey 2012). In this sense, Salovey and Mayer (1990), considered modern progenitors of emotional intelligence, proposed that emotional intelligence provides the ability to engage in appropriate "social functioning".

Based on the above, this study suggests that if the role of emotional intelligence is to induce prosocial awareness, attitudes, and behaviors, there will be a positive correlation between awareness of children's rights and emotional intelligence, since emotional intelligence is the ability to recognize and sympathize with the feelings and thoughts of others and the unique needs of children. 
This study is particularly pertinent to two issues of emotional intelligence. First, the literature on the formation of and changes in emotional intelligence in adults has discovered that parenting experiences in childhood have a great influence on childhood emotional intelligence. Second, the emotional intelligence formed in childhood tends to be preserved even when one is an adult. Although there are few systematic studies exclusively focusing on parenting style and emotional intelligence (Alegre 2011), it is true that positive parenting attitudes are reported to produce favorable outcomes for childhood and adolescent emotions and behaviors. (Bennet et al. 2005; Alegre and Benson 2007; Eisenberg, Fabes, Guthrie and Reiser 2000; Eigenberg, Fabes, Guthrie, Reiser and Shepard et al. 1999; Gottman et al. 1997). This new and creative interpretation of the literature of emotional intelligence in terms of its social function implies that it can significantly influence parents' awareness of their children's rights and their own parenting attitudes toward their children. In this study, parenting attitudes were classified into an acceptive attitude (positive) and a rejective attitude (negative), and the effect of these attitudes on the development of emotional intelligence was empirically verified.

It is also reported that the emotional intelligence formed through interaction with parents in childhood can continue even into adulthood. To the best of my knowledge, this has not been examined in the emotional intelligence literature. However, relevant evidence is often found in studies on 'empathy', which can be regarded as a proxy variable of emotional intelligence (Allemand et al. 2015; Grühn et al. 2008; Helson et al. 2002). The term empathy, utilized in studies dealing with psychological persistence, is defined as 'an ability to perceive, understand, and share the feelings of others' (Cox et al. 2012; Davis 2007; Grühn et al. 2008; Helson et al. 2002; Pizarro 2000). These components of empathy essentially correspond with subbranches in standard models of emotional intelligence, emotional perception, emotional expression, and empathy, which are measured and analyzed in this study. Therefore, from this literature, we can infer some theoretical intuitions useful for our own understanding of the properties of emotional intelligence. Recent longitudinal studies (Allemand et al. 2015; Grühn et al. 2008; Helson et al. 2002, and additional studies cited therein) on the development trajectory of empathy over an individual's entire life have commonly reached two conclusions: first, the basis of empathy is mainly formed in the early years of life (from infancy to adolescence). Second, empathy formed in these early years has a strong tendency to be continue into until adulthood.

These findings form a solid foundation for this study. First, they enable us to empirically analyze the relationship between the childhood experiences of mothers and their current emotional intelligence. Second, they indicate the value of investigating the effect of emotional intelligence on the level of awareness of children's rights. If it works as a 'social function' and the latter is considered to be a kind of social attitude, as discussed above, the greater the experience that mothers have with positive parenting, the higher their emotional intelligence and level of awareness of children's rights will be.

\section{lii. Model, Measurements And Data}

\section{Model and Hypothesis Development}


Based on the theoretical background supporting our new ideas discussed above, the present study builds an operable model to measure the relationship between the aforementioned factors (see Fig. 1). The model is based on the structural equation modeling approach, which implies that all conventions in the analysis of structural equation modeling apply. It is designed to capture how parenting experiences affect awareness of children's rights both directly and indirectly (mediated) through psychological factors. Importantly, parenting experiences are divided into acceptive (positive) and rejective (negative) experiences. In the figure below, the arrows connecting the variables in ovals can be interpreted as causal relationships representing the various implied hypotheses.

\section{Research Participants and Dataset}

Thus, this study intends to conduct research on mothers who are mostly in charge of child-rearing. (In general, the mothers in Korea take responsibility for child-rearing. This study focuses on Korean mothers only. There may be differences in research by countries depending on their subjects of study.) -add Reviewers

This study was conducted on Korean mothers with kindergartners considering that the childhood experience of mothers whom their young children spend most of their time with affects their parenting attitudes, which will impact the children's rights in the end. Including a survey of psychological factors, it was conducted on the mothers of infants aged 3 to 5 in kindergarten by random sampling through Naver Office (SNS). Before being proceeded, this survey had been approved by Bioethics Committee. It was conducted through various online communities for kindergartens and mothers. A total of 1,011 people participated in the survey, among which only 906 copies were used for analysis, excluding missing data and outliers. -add Reviewers

To empirically test the validity of the hypotheses, we surveyed and collected data from mothers in Korea with 3- to 5-year-old children who voluntarily participated in the survey through the Naver.com poll platform. A total of 1,011 participants completed the questionnaires designed to measure the relevant variables. By deleting incomplete samples, 906 samples were analyzed, which is sufficient to guarantee the reliability of the model estimation.

\section{Measurement Instruments}

The measurement instruments for the latent variables were as follows. To measure parenting experiences in participants' childhood, this study employed the modified Mother-Father-Peer Scale (MFPS), which was originally proposed by Epstein (1983) and was revised by Jeon (1997) to reflect Korean-specific characteristics. This instrument consists of 9 items for acceptive and rejective experiences with parents. To measure self-esteem, we use a Korean version of the Self-Esteem Inventory (SEI) for adults proposed by Kang (1986) and revised by Coopersmith (1967). Our shortened version of the SEl includes 25 items grouped into four subconstructs: interpersonal relationships (5 items), self-denial (4 items), leadership (4 items), and self-assertiveness \& disrespect (5 items). To measure emotional intelligence, we employed the emotional intelligence inventory for Korean adults developed by Moon (1998), which is based on the 
emotional intelligence model by Salovey and Mayer (1990). The instrument originally consisted of five subconstructs of emotional intelligence, including emotional perception, emotional expression, empathy, emotion regulation, and emotional utilization. To measure the social functions that are most relevant to awareness of children's rights, this study employed questions from the first three subconstructs (see the theoretical discussions above). Finally, we used the Korean version of Hart and Zeidner's (1993) questionnaire, which grew out of the United Nations Convention on the Rights of the Child (UNCRC) in 1989 , to measure the level of awareness of children's rights. The questionnaire consists of 40 items reflecting the UNCRC's three principles of children's rights. However, the questions have been rearranged and grouped into four operational subscales: the right to survival, the right to protection, the right to development, and the right to participate.

All questionnaires were measured using a 5-point Likert scale comprising the following answers: Very Important (have a lot) - 5 points; Somewhat Important (have some) - 4 points; Neutral (have an average amount) - 3 points; Less Important (have less than average) - 2 points; and Not Important (have none) 1 point. All instruments were verified for relevance and validity by a professor in the Department of Early Childhood Education and 3 doctorate degree holders.

\section{囚. Results}

Having ensured the validity and reliability of our data, the SEM was estimated. Table 2 shows that the representative indexes for SEM model fitness are fairly high, implying that the estimation results are reliable. Figure 1 graphically presents the final estimation results upon which we draw our conclusions, and Table 3 summarizes them numerically.

Table 1 and Table 3 provide estimated coefficients for all paths and the results of the statistical test. Table 1 shows that all coefficients for the measured variables are significant at the $1 \%$ level. However, as Table 3 shows, not all path coefficients among latent variables were significant. Acceptive childhood experiences had a statistically significant effect on emotional intelligence but not on self-esteem, while rejective childhood experiences had a statistically significant effect on self-esteem but not on emotional intelligence. Therefore, it is predicted that acceptive childhood experiences mainly affect awareness of children's rights via emotional intelligence, while rejective childhood experiences affect it via self-esteem.

Although the individual coefficients may provide some insights into how the model works, the total effects of the mediators cannot be separately estimated and inferred; instead, they should be estimated as a whole. This is done by a decomposition analysis that estimates and tests the total effects as a whole and then decomposes them into direct and indirect effects, testing those effects by the bootstrapping method. Table 4 presents the results of this decomposition analysis. First, the total and indirect effect of the acceptive experience on the awareness of children's rights is positive at a significance level of less than $1 \%$. In other words, mothers who had more acceptive experiences with their parents in childhood have higher emotional intelligence, and this indirectly raises their level of awareness of children's rights. 
Second, rejective parenting experiences have a strong and statistically significant total effect on the awareness of children's rights, although its direct and indirect effects appear to be positive but only slightly significant. This significant total effect may imply that the mothers with more rejective parenting experiences tend to be more aware of children's rights, which seems to be slightly contrary to common sense. As for the mediating effects of rejective experiences, the total effect of 0.201 consists of a direct effect of 0.121 and an indirect effect of only 0.08 , implying that the total effect depends, in large part, on the direct effect and much less on mediation effects. It is interesting to note that rejective parenting experiences are significantly and negatively associated with self-esteem with a standardized path coefficient of -0.517 . Combining this with the fact that the indirect effect of rejective parenting experiences on the awareness of children's rights is small and the fact that there is a minor and nonsnonignificant negative association between self-esteem and awareness, we can safely infer that self-esteem has, at best, a neutral relationship with the awareness of children's rights. This may be considered supportive evidence for the theory that self-esteem has no necessary implication for social behavior and attitudes.

In summary, the estimation result shows that parenting experiences in childhood can affect the formation and development of the psychological factors of emotional intelligence and self-esteem. It also demonstrates asymmetric mediation effects of the two psychological factors: that is, positive parenting experiences have significant indirect effects on the awareness of children's rights via emotional intelligence, while negative parenting experiences have a more prominent direct effect rather than an indirect (mediating) effect.

\section{Conclusion}

The purpose of this study is to provide an explanation for the well-documented close relationship between parenting experience in one's childhood and parenting attitude in adulthood, which has long remained a black box in the field. Given the lack of knowledge on the phenomenon, it is necessary to explore the possible channels through which the relationship may be realized. Combining the results from psychological investigations with those from studies on early childhood, the present study suggests the mediation effects of two psychological factors on the awareness of children's rights, in which psychological development is believed to be affected by parenting experiences in childhood. If it is the case and one can assume a positive association between parenting attitudes and the awareness of children's rights, this black box could be at least partially opened. These findings are in agreement with the previous findings in that parenting experience in childhood is related to parenting attitudes toward children and the awareness of children's rights. However, the contribution of this study is to show that parenting experience is related to such awareness through psychological development.

The results of this study have important policy implications and provide suggestions for raising awareness of children's rights and thereby preventing child abuse. First, to raise the level of awareness of 
children's rights, it is imperative to promote psychological factors among parents, especially emotional intelligence, since mothers' emotional intelligence appears to have a positive and significant influence on their awareness of children's rights. From a practical perspective, emotional intelligence can be learned and developed in the process of socialization rather than from genetic factors over an individual's entire life. We suggest programs for all adults that aim to enhance emotional intelligence.

Second, it should be noted that the psychological development that occurs through childhood experiences has a strong tendency to continue into adulthood. In particular, self-esteem and emotional intelligence are rapidly formed and developed beginning in early childhood, and a large part of these characteristics will be maintained as individuals age. Thus, psychological development in childhood can be considered to affect one's entire life. Therefore, having stable and positive psychological development in childhood is a very important first step in improving adults' awareness of children's rights.

Finally, and importantly, the factors that have the greatest influence on psychological development in childhood are parents' parenting attitudes. This is because the greatest source of social interaction for children and adolescents is parenting. The psychological factors formed th this time have a strong influence even into adulthood. The development of these factors and the social competence that follows will not only improve awareness of children's rights and thus improve family life but also serve as a crucial factor in determining quality of life throughout an individual's entire life by facilitating interpersonal relationships, job satisfaction, self-esteem, willpower and resilience to suffering.

Although it was conducted in a local perspective, this study suggests that mothers' childhood experience affects their parenting attitudes, which will impact children's rights. It is the parents' responsibility to recognize and relieve their children's stress when they are under childhood stress (Jon \& Myla, 2021). It can be said that having the ability to understand children's unique personalities and feelings and carefully listening to their voices in their place is a good parenting attitude as a parent. -add reviewers

\section{Declarations}

Competing interests: The authors declare no competing interests.

\section{References}

Alegre, A., \& Benson, M. (2007). Parental acceptance and late adolescents' adjustment: The role of emotional intelligence. In E. Fatos (Ed.), Acceptance: The essence of peace. (Selected Papers from the First International Congress on Interpersonal Acceptance and Rejection, pp. 33-49). Istanbul, Turkey: Turkish Psychology Association, Incekara Press.

Alegre, A. (2011). Parenting Styles and Children's Emotional Intelligence: What do We Know? The Family Journal: Counceling and Therapy for Couples and Families, 19(1), 56-62. 
Amy J.L.Baker., Marla R.Brassard., \& Janet Rosenzweig(2021). Psychological maltreatment: Definition and reporting barriers among American professionals in the field of child abuse. Child Abuse \& Neglect. Vol(114), April 2021, 104941 / online 29 January 2021.

Allemand, M., Steiger, A. E., \& Fend, H. A. (2015). Empathy Development in Adolescence Predicts Social Competencies in Adulthood. Journal of Personality, 83(2), 229-241.

Branden, N.(1995). The six pillars of self-esteem. New York: Bantam Book.

Baumeister, R. F., \& K. D. Vohs (2018). Revisiting Our Reappraisal of the (Surprisingly Few) Benefits of High Self-Esteem, Perspectives on Psychological Science, 13(2), 137-140.

Baumeister, R. F., Campbell, J. D., Krueger, J. I., \& Vohs, K. D. (2003). Does high self-esteem cause better performance interpersonal success, happiness, or healthier lifestyles? Psychological Science in the Public Interest, 4, 1-44.

Baumeister, R. F., Smart, L., \& Boden, J. M. (1996). Relation of threatened egotism to violence and aggression: The dark side of high self-esteem. Psychological Review, 103, 5-33.

Bennett, D. S., Bendersky, M., \& Lewis, M. (2005). Antecedents of emotion knowledge: Predictors of individual differences in children. Cognition \& Emotion, 19, 375-396.

Chakraborty, M., \& Chlup, D. T. (2016). The Relationship between Social Justice Issues and Emotional Intelligence: A Literature Review. in Ololube, N. P. (ed.) Handbook of Research on Organizational Justice and Culture in Higher Education Institutions, Hershey, PA: Information Science Reference, 205-223.

Cherniss, C. (2010). Emotional Intelligence: Toward Clarification of a Concept, Industrial and Organizational Psychology, 3, 110-126.

Cole, D. A., Maxwell, S. E., Martin, J. M., Peeke, L. G., Seroczynski, A. D., Tram, J. M., \& Maschman, T. (2001). The development of multiple domains of child and adolescent self-concept: A cohort sequential longitudinal design. Child Development, 72, 1723-1746.

Cooley, C. H. (1902). Human nature and the social order. New York, NY: Scribers.

Coopersmith, S. (1967). The antecedents of self-esteem. San Francisco: W. H. Freeman.

Crowell, J. A., \& Feldman, S. S. (1989). Mothers' internal models of relationships and children's behavioral and developmental status: A study of mother-child interaction. Psycscan Developmental Psychology, 10, 17.

Cox, C. L., Lucina Q. U., Adriana D. M., F Xavier Castellanos, Michael P. Milham \& Clare Kelly. (2012). The balance between feeling and knowing: affective and cognitive empathy are reflected in the brain's intrinsic functional dynamics. Social cognitive and affective neuroscience, 7(6), 727-737. 
Craig, C. (2006). A Short History of Self-Esteem.

Crocker, J., \& Park, L. E. (2004). The Costly Pursuit of Self-Esteem, Psychological Bulletin, 130(3), 392414.

Daus, C. S. \& Ashkanasy, N. M. (2003). Will the Real Emotional Intelligence Please Stand Up? On Deconstructing the Emotional Intelligence "Debate." The Industial-Organizational Psychologist, 41(2), 6972.

Davis, M. H. (2007). Empathy. in Stets, J.E. \& J.H. Turner (Eds.) Handbook of the Sociology of Emotions (p.443-466), New York: Springer.

Davis, M. H., Mitchell, K. V., Hall, J. A., Lothert, J., Snapp, T., \& Meyer, M. (1999). Empathy, expectations, and situational preferences: Personality influences on decision to participate in volunteer behaviors. Journal of Personality, 67, 469-503.

Donnellan, M. B., Kenny, D. A., Trzesniewski, K. H., Lucas, R. E., \& Conger, R. D. (2012). Using trait-state models to evaluate the longitudinal consistency of global self-esteem from adolescence to adulthood. Journal of Research in Personality, 46, 634-645.

Eisenberg, N., Fabes, R. A., Shepard, S. A., Guthrie, I. K., Murphy, B. C., \& Reiser, M. (1999). Parental reactions to children's negative emotions: Longitudinal relations to quality of children's social functioning. Child Development, 70, 513-534.

Eisenberg, N., Fabes, R. A., Guthrie, I. K., \& Reiser, M. (2000). Dispositional emotionality and regulation: Their role in predicting quality of social functioning. Journal of Personality and Social Psychology, 78, 136-157.

Eisenberg, N., Morris, A. S., McDaniel, B., \& Spinrad, T. L. (2009). Moral cognitions and prosocial responding in adolescence. In R. M. Lerner \& L. Steinberg (Eds.), Handbook of adolescent psychology (pp. 229-265). New York: John Wiley \& Sons.

Emler, N. (2001). Self-Esteem: the costs and Causes of Low Self-Worth. York, England: York Publishing Service Ltd.

Epstein, R. (1983). The positive side effects of reinforcement: A commentary on balsam and bondy. Journal of Applied Behavior Analysis, 18(1), 73-78.

Fincham, F. D. (1994). Understanding the association between marital conflict and child adjustment: Overview. Journal of Family Psychology, 8(2), 123.

Gardener, H. (1983). Frames of Mind: The Theory of Multiple Intelligences. NYC: Basic Books. 
Gerdes, K. E., Segal, E. A., Jackson, K. F., \& Mullins, J. L. (2011). Teaching Empathy: A Framework Rooted in Social Cognitive Neuroscience and Social Justice, Journal of Social Work Education, 47(1), 109-131.

Goleman, D. (1995). Emotional Intelligence. New York: Bantam.

Goleman, D. (1998). Working with emotional intelligence. New York: Bantam.

Goleman, D. (2006). Social Intelligence: The New Science of Human Relationships, New York: Bantam Gottman, J.M., Katz, L. F., \& Hooven, C. (1997). Meta-emotion. How families communicate emotionally. Mahwah, NJ: Lawrence Erlbaum.

Grühn, Daniel, Kristine Rebucal, Manfred Diehl, Mark Lumley and Gisela Labouvie-Vief. (2008). Empathy across the adult lifespan: Longitudinal and experience-sampling findings. Emotion, 8(6):753-765.

Hart \& Zeidner (1993). Children's rights perspectives of youth and educators: Early findings of a cross national project. International Journal of Children's Rights 1, 165-188.

Helson R, Jones C, Kwan VSY. (2002). Personality change over 40 years of adulthood: Hierarchical linear modeling analyses of two longitudinal samples. Journal of Personality and Social Psychology, 83: 752766.

Holland, A., $\otimes$ Andre, T. (1994). Athletic participation and the social status of adolescent males and females, Youth $\square$ Society, 25(3), 388-407.

James, W. (1890). Principles of Psychology, Vo1.1, New York: Henry Holt, 96-116.

Jeon, H. J. (1997). The effect of childhood experience, personality and marital satisfaction on childrearing behavior. Ewha Womans University Master's Thesis.

Jon Kabat-Zinn \& Myla Kabat-Zinn (2021). Mindful Parenting: Perspectives on the Heart of the Matter.

Jöreskog, K. G. \& D. Sörbom (1989). LISREL 7: a guide to the program and applications, Chicago: SPSS.

Kaiser, H. F. (1974). An index of factorial simplicity. Psychometrika, 39, 31-36.

Kang, J. G. (1986). Self-concept, Career Maturity and Academic Achievement. Seoul University Master's Thesis.

Laura-Émilie Savage., George M. Tarabulsy., Jessica Pearson., Delphine Collin-Vézina

\& Lisa-Marie Gagné(2019). Maternal history of childhood maltreatment and later parenting behavior: A meta-analysis. Published online by Cambridge University Press: 13 February 2019.

Locke, E. A. (2005). Why Emotional Intelligence is an Invalid Concept, Journal of Organizational Behavior, $26,425-431$. 
Lopes, P.N., Brackett, M.A., Nezlek, J.B., Schütz, A. Sellin, I., \& Salovey, P. (2004). Emotional Intelligence and Social Interaction, Personality and Social Psychology Bulletin, 30(8): 1018-1034.

Mathews, G. M., Emo, A. K., Roberts, R. D., \& Zeidner, M. (2006). What is this thing called emotional intelligence? in K. R. Murphy (Ed.), A Critique of Emotional Intelligence, $\mathrm{NJ}$ : Lawrence Erlbaum.

McDonald, N. M., \& Messinger, D. S. (2011). The development of empathy: How, when, and why. In J. J. Sanguineti, A. Acerbi, \& J. A. Lombo (Eds.), Moral behavior and free will: A neurobiological and philosophical approach (pp. 333-359). Rome: IF-Press.

McGuire, S., Neiderhiser, J. M., Reiss, D., Hetherington, E. M., \& Plomin, R. (1994). Genetic and environmental influences on perceptions of self-worth and competence in adolescence: A study of twins, full siblings, and step-siblings. Child Development, 65, 785-799.

Mitchell, R.J. (1993), Path Analysis: Pollination, in S.M. Schneider and J. Gurevitch edited, Design and Analysis of Ecological Experiments, New York: Chapmanand Hall, pp.211-231.

Moon, Yonglin. (1998). The present and future of Research on Emotional Intelligence, Proceedings of Korean Association of Child Studies, 198(2): 1-16.

Murphy, K. R. (2006). Four Conclusions about Emotional Intelligence. in K. R. Murphy (Ed.), A Critique of Emotional Intelligence, NJ: Lawrence Erlbaum.

Neiss, M. B., Sedikides, C., \& Stevenson, J. (2002). Self-esteem: A behavioural genetic perspective. European Journal of Personality, 16, 351-367.

Neiss, M. B., Stevenson, J., Sedikides, C., Kumashiro, M., Finkel, E. J., \& Rusbult, C. E. (2005). Executive self, self-esteem, and negative affectivity: Relations at the phenotypic and genotypic level. Journal of Personality and Social Psychology, 89, 593-606.

Orth, U. (2018). The Family Environment in Early Childhood has a Long-term Effects on Self-Esteem: A Longitudinal Study from Birth to Age 27 Years, Journal of Personality and Social Psychology, 114, pp.637-655.

Orth, U. (2017). The Lifespan Development of Self-Esteem, in J. Specht (Ed.), Personalitiy Development across the Lifespan (pp.181-195), London, UK: Elsevier.

Orth, U., Maes, J., \& Schmitt, M. (2015). Self-esteem development across the life span: A longitudinal study with a large sample from Germany. Developmental Psychology, 51, 248-259.

Orth, U., Robins, R. W., \& Widaman, K. F. (2012). Life-span development of self-esteem and its effects on important life outcomes. Journal of Personality and Social Psychology, 102, 1271-1288. 
Orth, U., Trzesniewski, K. H., \& Robins, R. W. (2010). Self-esteem development from young adulthood to old age: A cohort-sequential longitudinal study. Journal of Personality and Social Psychology, 98, 645658.

Orth, U., \& Robins, R. W. (2014). The development of self-esteem. Current Directions in Psychological Science, 23, 381-387.

Pizarro, D. (2000). Nothing More Than Feelings? The Role of Emotion in Moral Judgment, Journal for the Theory of Social Behaviour, 30(4), 355-375.

Pizarro, D., \& P. Salovey, (2012). Being and Becoming a Good Person: The Role of Emotional Intelligence in Moral Development and Behavior. in J. Aronson(Ed.), Improving Academic Achievement: Impact of Psychological Factors on Education (pp.247-266), San Diego: Academic Press.

Robins, R. W., \& Trzesniewski, K. H. (2005). Self-esteem development across the lifespan. Current Directions in Psychological Science, 14, 158-162.

Rogenberg, M. (1979). Conceiving the self. New York. Basic Books.

Salovey, P., \& Mayer, J. (1990). Emotional Intelligence. Imagination, Cognition, and Personality, 9, 185-211.

Thorndike, E. L. (1920). Intelligence and its uses. APA PsycNet, 140, 227-235.

Trzesniewski, K. H., Donnellan, M. B., \& Robins, R. W. (2013). Development of self-esteem. in V. Zeigler-Hill (Ed.), Self-esteem (pp. 60-79). London, UK: Psychology Press.

Wagner, J., Lüdtke, O., \& Trautwein, U. (2016). Self-esteem is mostly stable across young adulthood: Evidence from latent STARTS models. Journal of Personality, 84, 523-535.

Wechsler, D. (1958). The measurement and appraisal of adult intelligence. Baltimore, MD: Williams $₫$ Wilkins.

West, S.G., J. Finch \& P.J. Curran. (1995). Structural Models with Nonnormal Variables: Problems and remedies, in R.H. Hoyle (Ed.), Structural Equation Modeling: Concept, issues, and Applications (pp. 56-75), Tousand Oaks, CA: Sage.

Wilhelm, M. O., \& Bekkers, R. (2010). Helping behavior, dispositional empathic concern, and the principle of care. Social Psychology Quarterly, 73, 11-32.

Segye Ilbo(2020). http://www.segye.com/newsView/20210108512074?OutUrl=naver

Seoul Shinmun (2021). http://nownews.seoul.co.kr/news/newsView.php?id=20210208601012

\section{Tables}


Table 1 Convergence Validity Tests by CFA

Page 16/20 


\begin{tabular}{|c|c|c|c|c|c|c|c|c|}
\hline \multicolumn{2}{|l|}{$\begin{array}{l}\text { Observed } \\
\text { Variables }\end{array}$} & $\begin{array}{l}\text { Latent } \\
\text { Variables }\end{array}$ & Standard & Nonstd & S.E. & C.R. & AVE & CR \\
\hline Acceptive1 & $\leftarrow$ & $\begin{array}{l}\text { Rejective } \\
\text { Experience }\end{array}$ & 0.747 & 1 & & & & \\
\hline Acceptive2 & $\leftarrow$ & $\begin{array}{l}\text { Rejective } \\
\text { Experience }\end{array}$ & 0.821 & 1.032 & 0.047 & 22.133 & 0.5 & 0.749 \\
\hline Acceptive3 & $\leftarrow$ & $\begin{array}{l}\text { Rejective } \\
\text { Experience }\end{array}$ & 0.709 & 0.95 & 0.048 & 19.712 & & \\
\hline Rejective1 & $\leftarrow$ & $\begin{array}{l}\text { Acceptive } \\
\text { Experience }\end{array}$ & 0.694 & 1 & & & & \\
\hline Rejective2 & $\leftarrow$ & $\begin{array}{l}\text { Acceptive } \\
\text { Experience }\end{array}$ & 0.778 & 1.102 & 0.058 & 19.157 & 0.489 & 0.742 \\
\hline Rejective3 & $\leftarrow$ & $\begin{array}{l}\text { Acceptive } \\
\text { Experience }\end{array}$ & 0.746 & 0.91 & 0.049 & 18.673 & & \\
\hline Self-Denial & $\leftarrow$ & Self-esteem & 0.803 & 1 & & & & \\
\hline Relations & $\leftarrow$ & Self-esteem & 0.686 & 0.828 & 0.041 & 20.316 & 0.706 & 0.877 \\
\hline Leadership & $\leftarrow$ & Self-esteem & 0.854 & 1.149 & 0.048 & 23.819 & & \\
\hline Empathy & $\leftarrow$ & $\begin{array}{l}\text { Emotional } \\
\text { Intelligence }\end{array}$ & 0.624 & 1 & & & & \\
\hline $\begin{array}{l}\text { Emotional } \\
\text { Expression }\end{array}$ & $\leftarrow$ & $\begin{array}{l}\text { Emotional } \\
\text { Intelligence }\end{array}$ & 0.654 & 1.067 & 0.077 & 13.8 & 0.745 & 0.897 \\
\hline $\begin{array}{l}\text { Emotional } \\
\text { Perception }\end{array}$ & $\leftarrow$ & $\begin{array}{l}\text { Emotional } \\
\text { Intelligence }\end{array}$ & 0.736 & 1.069 & 0.075 & 14.21 & & \\
\hline Participation & $\leftarrow$ & $\begin{array}{l}\text { ChildRight } \\
\text { Awareness }\end{array}$ & 0.96 & 1 & & & & \\
\hline Development & $\leftarrow$ & $\begin{array}{l}\text { ChildRight } \\
\text { Awareness }\end{array}$ & 0.957 & 1.004 & 0.014 & 69.388 & & \\
\hline Protection & $\leftarrow$ & $\begin{array}{l}\text { ChildRight } \\
\text { Awareness }\end{array}$ & 0.954 & 1.037 & 0.015 & 68.171 & 0.862 & 0.962 \\
\hline Survival & $\leftarrow$ & ChildRight & 0.923 & $\begin{array}{l}0.948 \\
120\end{array}$ & 0.016 & 57.714 & & \\
\hline
\end{tabular}


Table 2 Estimation of Model Fit Indexes

\begin{tabular}{|ccccccc|}
\hline Indexes & GFI & AGFI & TLI & CFI & RMR & RMSEA \\
\hline 4.885 & 0.94 & 0.914 & 0.962 & 0.962 & 0.051 & 0.066 \\
& & & & & & \\
\hline
\end{tabular}

Table 3 Estimations of Path Coefficients among Latent Variables

\begin{tabular}{|c|c|c|c|c|c|c|c|}
\hline \multirow[t]{2}{*}{ Latent Variables } & & & \multicolumn{2}{|c|}{ Coefficients } & \multirow[t]{2}{*}{ S.E. } & \multirow[t]{2}{*}{ C.R. } & \multirow{2}{*}{$\begin{array}{l}\mathrm{P} \text { - } \\
\text { value }\end{array}$} \\
\hline & & & Nonstd & Standardized & & & \\
\hline $\begin{array}{l}\text { Emotional } \\
\text { Intelligence }\end{array}$ & $\leftarrow$ & $\begin{array}{l}\text { Acceptive } \\
\text { Experience }\end{array}$ & 0.264 & 0.481 & 0.046 & 5.807 & $\star \star \star$ \\
\hline Self-esteem & $\leftarrow$ & $\begin{array}{l}\text { Acceptive } \\
\text { Experience }\end{array}$ & 0.061 & 0.093 & 0.042 & 1.439 & 0.15 \\
\hline Rights Awareness & $\leftarrow$ & $\begin{array}{l}\text { Acceptive } \\
\text { Experience }\end{array}$ & 0.073 & 0.077 & 0.068 & 1.07 & 0.285 \\
\hline $\begin{array}{l}\text { Emotional } \\
\text { Intelligence }\end{array}$ & $\leftarrow$ & $\begin{array}{l}\text { Rejective } \\
\text { Experience }\end{array}$ & 0.045 & 0.088 & 0.039 & 1.141 & 0.254 \\
\hline Self-esteem & $\leftarrow$ & $\begin{array}{l}\text { Rejective } \\
\text { Experience }\end{array}$ & -0.313 & -0.517 & 0.042 & -7.486 & 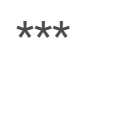 \\
\hline Rights Awareness & $\leftarrow$ & $\begin{array}{l}\text { Rejective } \\
\text { Experience }\end{array}$ & 0.106 & 0.121 & 0.064 & 1.674 & 0.094 \\
\hline Rights Awareness & $\leftarrow$ & Self-esteem & -0.124 & -0.086 & 0.067 & -1.848 & 0.065 \\
\hline Rights Awareness & $\leftarrow$ & $\begin{array}{l}\text { Emotional } \\
\text { Intelligence }\end{array}$ & 0.697 & 0.405 & 0.083 & 8.403 & $\star \star \star$ \\
\hline
\end{tabular}

Table 4 Decomposition Analysis 


\begin{tabular}{lllcc}
\hline \multicolumn{1}{c}{ Paths } & & Direct Effect & Indirect Effect & Total Effect \\
\hline Acceptive Experience & $\rightarrow$ Self-esteem & 0.093 & - & 0.093 \\
& $\rightarrow$ Emotional Intelligence & $0.481^{* * *}$ & - & $0.481^{* * *}$ \\
& $\rightarrow$ Rights Awareness & 0.077 & $0.187^{* * *}$ & $0.264^{* * *}$ \\
& $\rightarrow$ Self-esteem & $-0.517^{* * *}$ & - & $-0.517^{* * *}$ \\
& $\rightarrow$ Emotional Intelligence & 0.088 & - & 0.088 \\
& $\rightarrow$ Rights Awareness & $0.121^{*}$ & $0.080^{*}$ & $0.201^{* * *}$ \\
& & & & - \\
Self-esteem & $\rightarrow$ Rights Awareness & -0.086 & - & -0.086 \\
& & & & $0.405^{* *}$ \\
Emotional Intelligence & $\rightarrow$ Rights Awareness & $0.405^{* * *}$ & & \\
& & &
\end{tabular}

Note: The statistical tests were conducted by the bootstrap method.

\section{Figures}




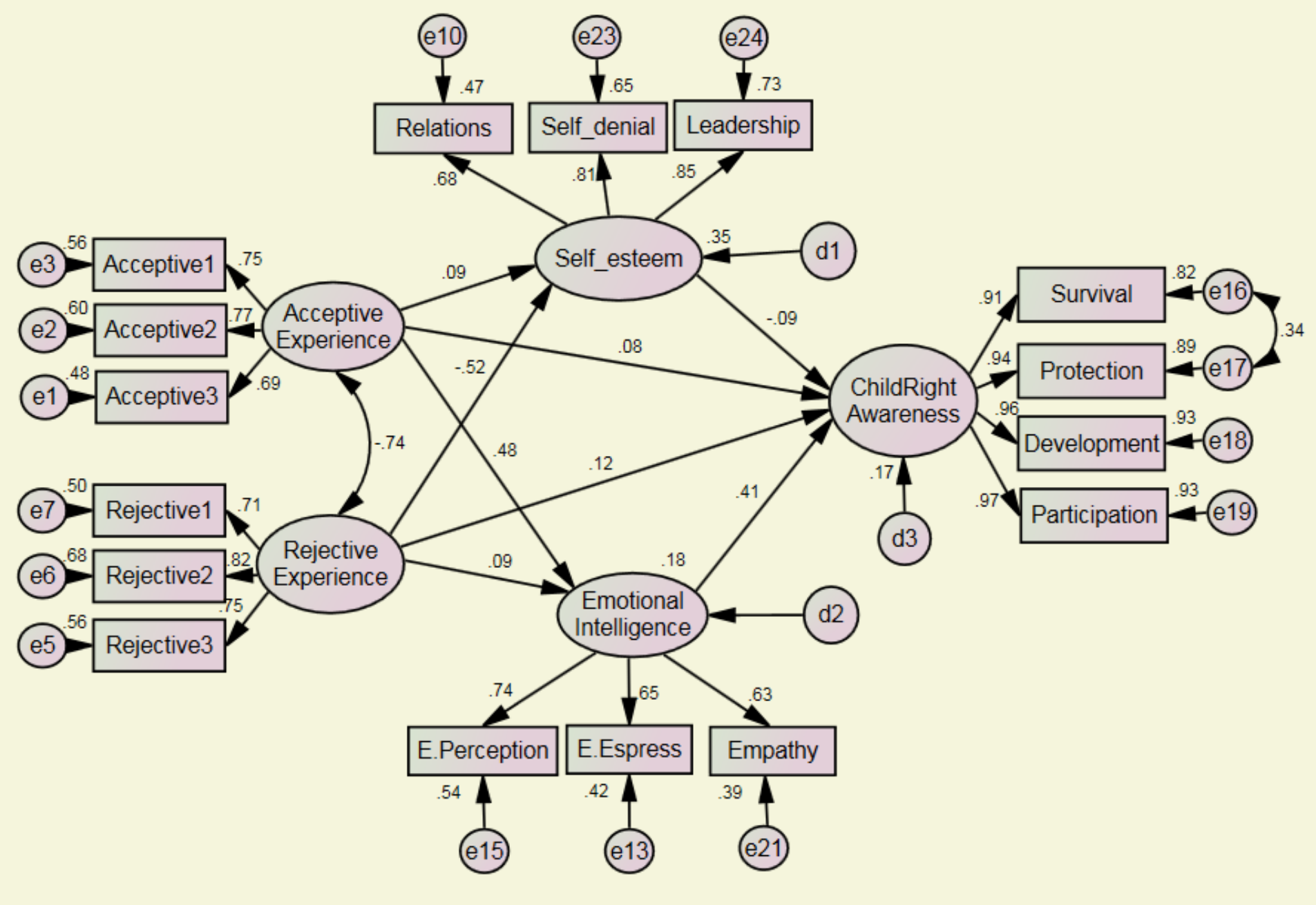

Figure 1

Estimation Result of the Structural Equation Model 